Check for updates

Cite this: Chem. Sci., 2018, 9, 6532

๑ All publication charges for this article have been paid for by the Royal Society of Chemistry

Received 12th April 2018

Accepted 4th July 2018

DOI: $10.1039 / \mathrm{c} 8 \mathrm{sc} 01675 \mathrm{e}$

rsc.li/chemical-science

\section{Biomass-mediated ZSM-5 zeolite synthesis: when self-assembly allows to cross the Si/Al lower limit $\uparrow$}

\author{
Marcelo Maciel Pereira, (DD a Elisa Silva Gomes, ${ }^{a}$ Alessandra Vieira Silva, ${ }^{a}$ \\ Ana Belen Pinar, ${ }^{b}$ Marc-Georg Willinger, ${ }^{c}$ Sangaraju Shanmugam, (D) \\ Céline Chizallet, (D) ${ }^{\mathrm{e}}$ Guillaume Laugel, ${ }^{f}$ Pit Losch $^{\mathrm{g}}$ and Benoît Louis (D) *g
}

A family of Al-rich ZSM-5 zeolites with $\mathrm{Si} / \mathrm{Al}=8 \pm 0.5$ was prepared according to a biomass-mediated supramolecular approach. A combination of advanced characterisation techniques and periodic density functional theory (DFT) calculations unraveled the purity and stability of un-expected Al-enriched ZSM-5 structures, hence allowing to cross the frontier of Si/Al lower limit. In addition, these Al-rich ZSM-5 zeolites demonstrated high catalytic activity in $n$-hexane cracking and methanol conversion into hydrocarbons, being in line with the presence of numerous Brønsted acid sites.

\section{Introduction}

The spontaneous self-organisation of matter demonstrates the capacity of nature to structure itself under appropriate conditions. The design and control of chemical systems ranging from the molecule up to the crystal represents one of the greatest challenges in science. ${ }^{\mathbf{1 , 2}}$ More precisely, it remains crucial to understand how molecules organise and build supramolecular architectures in order to produce functional nanomaterials. Supramolecular chemistry deals with an association of (at least) two chemical species through non-covalent interactions. ${ }^{2}$ The nature of these interactions often confers to the supramolecular structure new chemical and physical properties, defined by the nature of individual building blocks. ${ }^{3}$ The driving force of the assembly process can be van der Waals, electrostatic forces, hydrogen bonding, metal-ion coordination. ${ }^{2-5}$ Heterogeneous catalysis may also take advantage from the specific properties

${ }^{a}$ Universidade Federal do Rio de Janeiro, Centro de Tecnologia, Departamento de Química Inorgânica, Avenida Athos da Silveira Ramos, 149, Ilha do Fundão, 21941-909, Rio de Janeiro, RJ, Brazil

${ }^{b}$ Laboratory for Catalysis and Sustainable Chemistry, ETH Zürich, Paul Scherrer Institute, $\mathrm{CH}-5232$ Villigen, Switzerland

${ }^{c}$ Department of Inorganic Chemistry, Fritz Haber Institute of the Max Planck Society, Faradayweg 4-6, Berlin 14195, Germany

${ }^{d}$ Department of Energy Systems and Engineering, Daegu Gyeongbuk Institute of Science and Technology (DGIST), 50-1 Sang-Ri, Hyeongpung-Myeon, Dalseong-gun, Daegu, 711-873, Republic of Korea

${ }^{e}$ IFP Energies Nouvelles, Ront-point de l'échangeur de Solaize, BP3, 69360 Solaize, France

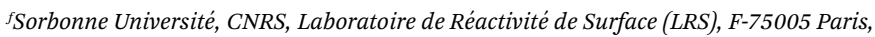
France

${ }^{g}$ Université de Strasbourg, CNRS, ICPEES, UMR 7515, 67000 Strasbourg, France. E-mail: blouis@unistra.fr

$\dagger$ Electronic supplementary information (ESI) available. See DOI: $10.1039 / \mathrm{c} 8 \mathrm{sc} 01675 \mathrm{e}$ induced by self-assembly processes. ${ }^{6,7}$ Usually, a catalyst is itself a meta-stable material produced while trapping an out-ofequilibrium state. ${ }^{8-11}$ However, critical challenges encountered in materials design stem from an inability to a priori tune crystal composition. ${ }^{8 c}$ Given the prominent use of zeolites as catalysts in industry as well as their strong potential for established and emerging technologies, ${ }^{\mathbf{9}, 10}$ it is necessary to find out suitable strategies to systematically engineer 'super big-two' FAU and MFI zeolites with defined properties. ZSM-5 is a highly siliceous zeolite $(\mathrm{Si} / \mathrm{Al}>10)$ currently used in several key acid-catalysed processes such as hydrocarbon cracking, methanol-to-olefins, isomerisation, alkylation. ${ }^{9}$ Zeolite catalyst design remains often hampered by a limited understanding of the relationship between crystal structure (along with acid site location) and catalytic activity/selectivity. It is worth mentioning that the activity is often proportional to the Al-content within the zeolite frame: i.e.; the lower $\mathrm{Si} / \mathrm{Al}$ ratio, the more acid sites, the higher was the hydrocarbon cracking activity as shown by Haag et al. ${ }^{9 c}$ For instance, *BEA zeolites with low $\mathrm{Si} / \mathrm{Al}<5$ have been recently synthesized without any organic structure directing agent (OSDA). ${ }^{12}$ Those Al rich *BEA catalysts demonstrated superior catalytic performance in the benzene alkylation with ethylene. ${ }^{\mathbf{1 2 c}, \boldsymbol{d}}$

Fundamental studies able to provide in-depth molecularlevel and supramolecular-level understanding of the zeolite crystallisation mechanisms are warranted for the design and optimisation of materials with superior properties for a large palette of applications. ${ }^{11}$ Often, the use of a set of in situ and ex situ characterisation techniques ranging from electron microscopy, to NMR and IR and to X-ray scattering are required to draw conclusions on the self-assembly guided crystallisation processes. The Rimer group has elegantly demonstrated the possible mimicking of biomineralisation processes, wherein crystallisation and self-assembly of hierarchically-structured 
zeolite materials was mediated by adsorbate-crystal interactions. ${ }^{8 a, b}$ Indeed, zeolite growth modifiers (polyamines, sugars) were used for molecular recognition and preferential binding to zeolite surfaces to alter the size and morphology of the crystals. ${ }^{13}$

Herein, we report the synthesis of zeolites using cheap sugar cane residues as crystal growth modifiers. A family of ZSM-5 zeolites exhibiting the lowest $\mathrm{Si} / \mathrm{Al}=8$ reported to date was designed following this strategy. Those catalysts were shown to exhibit a remarkable $n$-hexane cracking activity (based on Alcontent), being superior to state-of-the art ZSM-5 zeolites.

\section{Materials and methods}

\section{Preparation and characterisation of biomass derivates solution}

Un-treated sugar cane bagasse $(0.3 \mathrm{~g})$ was immersed in a $150 \mathrm{~mL}$ sodium hydroxide alkaline solution $(\mathrm{pH}=11)$. Alkaline hydrolysis of biomass was conducted for $24 \mathrm{~h}$ at either room temperature or $60{ }^{\circ} \mathrm{C}$. After filtration and removal of the fibers, $30 \mathrm{~mL}$ of the solution containing biomass-derivate compounds (extracted from the biomass), was used for the zeolite synthesis. Additionally, un-treated sugar cane bagasse was washed eight times in water at room temperature (until removing all extractives from the biomass on the basis of TG/DTG analyses). Both washed biomass and residues after hydrolysis were characterised by thermogravimetric (TG) and differential thermogravimetric (DTG) techniques (Fig. S1-S4†). The solution containing extracted compounds from the biomass was analysed by both liquid chromatography coupled with MS-MS (LC) and gel permeation chromatography (GPC). Detailed procedures are given in ESI. $\dagger$

Fig. S5 $\uparrow$ presents the GPC of washed sugar cane solution. Biomass-derivate compounds in the range of 1596-3178 daltons were observed. Considering that DTG indicates a reduction of hemicellulose fraction during hydrolysis step, the solution probably contains polysaccharides built by 14-21 xylose units, corresponding to $4-10 \mathrm{~nm}$ in length (depending on polymers branching). LC results (Fig. S6-S14 $\dagger$ ) reveal that the solution contains small amounts of sucrose and derivatives from coumaric and ferulic acids. Along with the presence of those saccharide oligomers, the solution obtained by hydrolysis of untreated biomass contain higher amount of sucrose and hexoses compared to the one of washed biomass.

\section{ZSM-5 zeolite synthesis with $\mathbf{S i} / \mathbf{A l}=8$}

The general synthesis approach consisted in adding to $30 \mathrm{~mL}$ of the solution containing biomass-derivate compounds, under vigorous stirring, $0.15 \mathrm{~g} \mathrm{NaAlO}_{2}$ and $8 \mathrm{~mL}$ tetrapropyl ammonium hydroxide (TPAOH, 20\% wt in water). In parallel, $0.76 \mathrm{~g}$ $\mathrm{NaCl}$ was dissolved in $30 \mathrm{~mL}$ distilled water. Finally, $6 \mathrm{~mL}$ tetraethylorthosilicate (TEOS) was added dropwise to the solution. The solution with the following mole ratios: $\mathrm{NaAlO}_{2}$ : TPA$\mathrm{OH}:$ TEOS : $\mathrm{NaCl}: \mathrm{H}_{2} \mathrm{O}=1: 28: 14: 7: 3857$, was allowed to age under stirring $(750 \mathrm{rpm})$ for $1 \mathrm{~h}$ at room temperature and then autoclaved at $443 \mathrm{~K}$ for 24 to $65 \mathrm{~h}$. About $1.25 \mathrm{~g}$ of white solid was obtained after Millipore membrane filtration and drying at $393 \mathrm{~K}$ overnight. This sample is named ZSM-5 SAR8. In parallel, ZSM-5-a and ZSM-5-b samples were synthesized using washed hydrolysate solution and alkaline hydrolysate at $60{ }^{\circ} \mathrm{C}$, respectively (all other synthesis parameters remaining the same).

\section{Characterisation of ZSM-5 zeolites with $\mathrm{Si} / \mathrm{Al}=\mathbf{8}$}

The samples were characterised by XRD with structure refinement performed using synchrotron techniques, ${ }^{14-18}$ SEM, HRTEM coupled with EDX mapping of the elements, ${ }^{27} \mathrm{Al}$ MAS NMR and FT-IR. As-prepared and calcined samples were investigated by XRD techniques, whilst calcined and exchanged $\mathrm{H}$-forms were investigated by electron microscopies, FT-IR of adsorbed pyridine and MAS NMR technique. Acidity measurements were performed to assess the total number of Brønsted acid sites using home-made H/D isotope exchange method. ${ }^{19}$ Textural properties were evaluated by nitrogen physisorption experiments. ${ }^{20}$ Details of all techniques are given in ESI. $\dagger n$-Hexane cracking experiments were performed in a high throughput unit at $773 \mathrm{~K}$ as described elsewhere and detailed in ESI. $\dagger^{21}$ Periodic Density Functional Theory (DFT) calculations were performed with the VASP $\operatorname{code} \mathrm{e}^{22}$ with the PBE (Perdew, Burke, and Ernzerhof) exchange-correlation functional. ${ }^{23}$ Details are given in ESI $\dagger$ illustrated with appropriate references. ${ }^{24,25}$

\section{Results}

\section{Structure solution of ZSM-5 prepared with the assistance of biomass}

The MFI-type framework structure is built by two sets of intersecting 10-ring channels, with straight channels that run parallel to the $b$ axis and sinusoidal channels running parallel to the $a$ axis. $^{26}$ A reversible transition from monoclinic to orthorhombic symmetry can readily occur at room temperature when organic molecules are occluded within the pores. ${ }^{27}$

Fig. 1A shows the diffraction pattern of ZSM-5 SAR8 zeolite. In spite of the sole presence of MFI structure, it appears that some peaks cannot be indexed using conventional orthorhombic unit cell (Pnma space group). It was reasoned that they could be super lattice reflections due to $\mathrm{Al}$ ordering, but these extra-reflections are usually weaker than those observed in Fig. 1A. A careful inspection of the XRD pattern showed that most of those extra-reflections appear as shoulders at slightly smaller $2 \theta$ angles than the main peaks, hence forming doublets in those peaks (Fig. 1B). A two-phase structure refinement was initiated in that space group using published atomic coordinates. ${ }^{27 \boldsymbol{b}}$ According to Rietveld refinement (Table S2 $\dagger$ ), cell dimensions are significantly lower than those from mutinaite, MFI natural analogue, for both refined phases. Mutinaite with a similar $\mathrm{Si} / \mathrm{Al}$ and cations, which is more likely to produce narrower T-O-T angles, exhibits an increase in the cell dimensions.

One may a priori expect an increase in the unit cell at higher Al-loadings. However, MFI zeolite is not cubic, therefore 
(A)

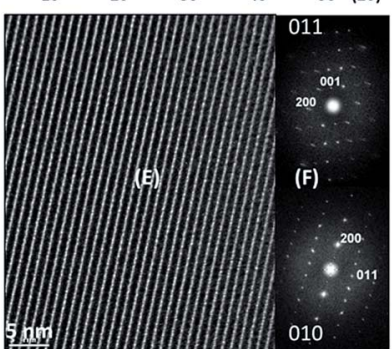

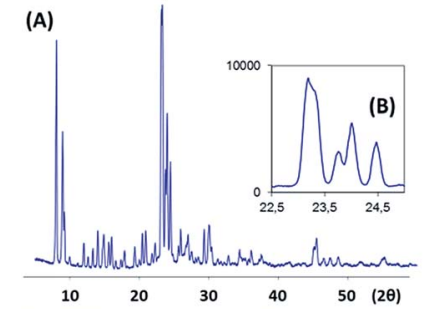
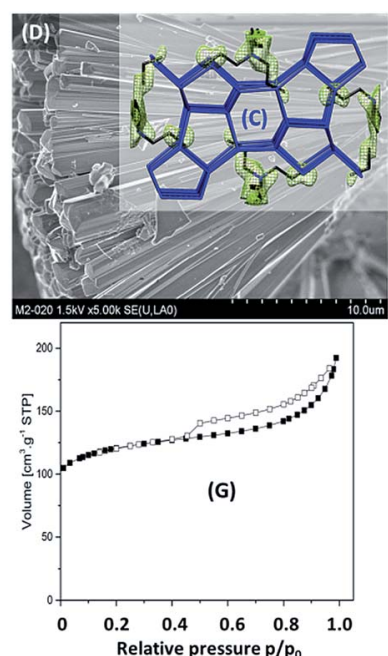

Fig. 1 (A) XRD pattern of Na-[TPA]-ZSM-5 SAR8 zeolite. The pattern could neither be indexed using the conventional orthorhombic unit cell nor in the monoclinic symmetry; (B) focus on MFI main reflections between $22.5-25^{\circ}$. It is noteworthy that those extra-reflections at smaller $2 \theta$ angles can be indexed in the same Pnma space group but with slightly larger unit cell parameters (Table S2†); (C) difference electron density map of the two phases showing an electron density cloud that resembled the shape of a TPA ${ }^{+}$cation located at the intersection of the straight with the sinusoidal 10 -ring channels of $\mathrm{Na}$ [TPA]-ZSM-5 SAR8 zeolite. $\mathrm{Na}^{+}$cations were not located in any of the two phases in the refinement, probably because they are disordered. The relative amounts of each phase refined to 71.8 for the main phase (with larger unit cell parameters) and 28.2 for the second phase (with a smaller unit cell). The crystallographic data for this structure are given in Table $\mathrm{S} 2 \uparrow$ along with selected interatomic distances and bond angles. The Lorentzian profile fit is shown in Fig. S15; $\uparrow$ (D) SEM image of $\mathrm{H}$-ZSM-5 SAR8 zeolite. An assembly into a cauliflower particle having tenths of micrometers in diameter can be observed. It seems that a nodal point served as a starting matter for those elongated needlelike shaped crystals growth; (E) HRTEM images of H-ZSM-5 SAR8 sample showing the high regularity of micropore arrays; (F) HAADF images confirm the sole formation of the MFI structure; $(G)$ nitrogen adsorption-desorption isotherm for H-ZSM-5 SAR8 zeolite.

changes in the $\mathrm{Al}$ content are not directly reflected in the unit cell parameters; one may expand in one direction and pull in another direction. While adding ethylene glycol to the gel, Camblor et al. observed shortening of the cell dimensions with a raise in the $\mathrm{Al}$ content. ${ }^{27 c}$ We could not see any shift in the XRD patterns between the Na- and H-zeolite forms as it could be expected if the small cell parameters were induced by a narrowing of T-O-T angles due to interactions with cations (they should relax in the H-form to something that is significantly larger).

A difference electron density map of each of the two phases showed an electron density cloud that resembled the shape of a $\mathrm{TPA}^{+}$cation located at the intersection of the straight with the sinusoidal 10-ring channels (Fig. 1C), being the position usually found for $\mathrm{TPA}^{+}$cations occluded in ZSM-5. FT-IR measurements also confirmed the presence of a band at $544 \mathrm{~cm}^{-1}$, being characteristic for MFI framework vibration. ${ }^{28}$ Fig. S16 $\dagger$ and 1D show the SEM images for as-obtained samples after $24 \mathrm{~h}$ and $65 \mathrm{~h}$ autoclaving, respectively. After a $24 \mathrm{~h}$ synthesis, the formation of rather un-defined structures could be observed $(300-500 \mathrm{~nm})$ rising from a nodal point (Fig. S16†). Though, this material remained barely crystalline (Fig. S17 $\dagger$ ), main reflections from the MFI structure could already be detected. By further prolongation of the synthesis duration to $65 \mathrm{~h}$, MFI crystals exhibit a needle-like morphology with an average length of $20 \mu \mathrm{m}$ (Fig. 1D). In stark contrast, the synthesis performed in the absence of biomass-derivate compounds resulted in conventional coffin-shaped crystals $(\mathrm{Si} / \mathrm{Al}=18)$. HRTEM images of ZSM-5 SAR8 sample were acquired with two different equipments (Fig. 1E). Both sets of images assess the extremely high regularity of the pores structure. High angle annular dark-field images (HAADF) further confirmed the high crystallinity and clearly evidenced the sole formation of MFI zeolite structure (Fig. 1F). Nitrogen adsorption-desorption isotherm (Fig. 1G) measurements have been performed to further get insights on such high Al-content ZSM-5 zeolite. ZSM-5 SAR8 zeolite exhibited an apparent BET specific surface area (SSA) value of $392 \mathrm{~m}^{2} \mathrm{~g}^{-1}$ among which $100 \mathrm{~m}^{2} \mathrm{~g}^{-1}$ corresponding to mesoporous surface (Table 1). Hence it is confirmed that SAR8 possesses a predominantly microporous structure. In line with those data, Fig. 1G confirms a type IV isotherm with the presence of a hysteresis loop, indicating the presence of well-defined mesoporosity. The morphology of the crystals (Fig. 1D) also suggested the presence of mesopores (or macropores) in intercrystalline voids created during the crystal growth process. ${ }^{29}$ It is important to mention that the mean diameter of the mesopores and the size of polysaccharides are in the same range (5-6 $\mathrm{nm})$.

TEM-EDX mapping confirmed the homogeneous distribution of both $\mathrm{Al}$ and $\mathrm{Si}$ elements and no $\mathrm{Al}$ enrichment zone could be observed (Fig. 2A). ${ }^{27} \mathrm{Al}$ MAS NMR of calcined and exchanged H-ZSM-5 SAR8 sample exhibited one sole and narrow signal at $51 \mathrm{ppm}$, supporting the presence of tetrahedral aluminium within the zeolite frame (Fig. 2B). The presence of (NMR visible) extra-framework aluminium (EFAl) species can therefore be discarded, thus confirming that $\mathrm{Si} / \mathrm{Al}$ ratio is related to solely framework aluminium. However, Lercher and co-workers have shown that invisible EFAl species could be present which may significantly hinder the catalyst performance. ${ }^{42,43}$ Pyridine adsorption confirmed the nearly absence of the vibration at $1455 \mathrm{~cm}^{-1}$ corresponding to Lewis acid sites (Fig. S25 $\dagger$ ). The ratio between the bands at $1546 \mathrm{~cm}^{-1}$ (Brønsted acid sites) and $1455 \mathrm{~cm}^{-1}$ (Lewis acid sites) ${ }^{48}$ could be estimated superior to 20 (i.e. $<0.08 \mathrm{mmol}$ of Lewis sites per gram).

The acidity of ZSM-5 SAR8 zeolite was quantitatively determined by $\mathrm{H} / \mathrm{D}$ isotope exchange titration technique. ${ }^{19} \mathrm{~A}$ value of $1.64 \mathrm{mmol} \mathrm{H}^{+}$per $\mathrm{g}$ zeolite was measured which roughly corresponds to $\mathrm{Si} / \mathrm{Al}=8.5$. Besides, elemental analyses further ascertained an MFI framework extremely rich in aluminium 7.6 $<\mathrm{Si} / \mathrm{Al}<8.5$ (Table 1).

In order to extend the scope of our strategy, a family of high Al-content ZSM-5 zeolites was prepared in the presence of solutions of biomass-derivatives as presented in Table 1: (i) hydrolysis of washed sugar cane keeping the other synthesis parameters identical as for ZSM-5 SAR8 (named ZSM-5-a); (ii) raising the alkaline hydrolysis temperature to $60{ }^{\circ} \mathrm{C}(\mathrm{pH}=10)$ 
Table 1 Elemental analyses, number of hydrons, apparent BET area, percentage of mesoporosity and synthesis yield are given for high Alcontaining ZSM-5 samples, plus SAR27 reference zeolite

\begin{tabular}{llllll}
\hline Sample & $\begin{array}{l}\mathrm{Si}^{\prime} \mathrm{Al}^{a} \\
{\left[\mathrm{~mol} \mathrm{~mol}^{-1}\right]}\end{array}$ & $\begin{array}{l}\text { Number of BA sites } \\
{\left[\mathrm{mmol} \mathrm{H}{ }^{+} \text {per g] }\right.}\end{array}$ & $\begin{array}{l}\text { Specific surface } \\
\text { areas }\left[\mathrm{m}^{2} \mathrm{~g}\right]\end{array}$ & $\begin{array}{l}\text { Degree of } \\
\text { mesoporosity }{ }^{c}[\%]\end{array}$ & $\begin{array}{l}\text { Synthesis yield } \\
(\mathrm{based} \mathrm{on} \mathrm{Si)}[\%]\end{array}$ \\
\hline ZSM-5 SAR8 & 8.5 & 1.64 & 392 & 26 & 58 \\
ZSM-5-a & 7.6 & 1.72 & 239 & 21 & 57 \\
ZSM-5-b & 8.2 & 1.63 & 207 & 21 & 52 \\
ZSM-5 SAR27 & 27 & 0.53 & 375 & 32 & 64
\end{tabular}

${ }^{a}$ Determined by XRF (and ICP-AES for ZSM-5 SAR8 sample). ${ }^{b}$ Determined by H/D isotope exchange technique. ${ }^{c}$ Degree of mesoporosity, $S_{\text {meso }} /$ $\left(S_{\text {meso }}+S_{\text {micro }}\right)$.

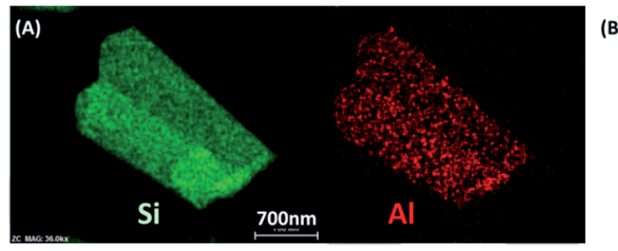

(B)
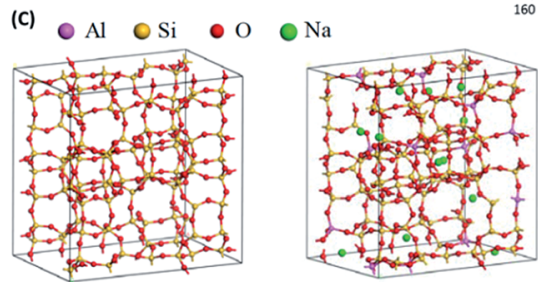

(c)
Fig. 2 (A) TEM EDX mapping of Al, Si elements; (B) ${ }^{27}$ Al MAS NMR of ZSM-5 SAR8 zeolite; (C) optimized cells calculated by DFT for (A) SAR $=\infty, n_{\mathrm{Al}}=0$, (B) $\mathrm{SAR}=7, n_{\mathrm{Al}}=12$, (C) $\mathrm{SAR}=2, n_{\mathrm{Al}}=32$.

during $24 \mathrm{~h}$ and using washed sugar cane (ZSM-5-b). These syntheses yielded solely MFI crystalline phase presence on the basis of XRD (Fig. S18 $\dagger$ ). A deeper focus on the XRD pattern also assesses the presence of extra-reflections, as shoulders at slightly smaller $2 \theta$ angles than the main peaks, forming doublets in those peaks (Fig. S18, $\uparrow$ inset) as already shown for ZSM-5 SAR8 zeolite (Fig. 1B). The crystal morphology consists of an aggregation of rod-like nanocrystals (Fig. S19†) as observed in previous studies involving biomass residues..$^{29,30}$

Based on data shown in Table 1, all ZSM-5 samples were obtained with similar yields and $7.6<\mathrm{Si} / \mathrm{Al}<8.5$ in the presence of solutions containing sugars. By raising the alkaline hydrolysis temperature to $60{ }^{\circ} \mathrm{C}$, sugars from hemicellulose and cellulose fractions were further released in the gel and allowed to produce a ZSM-5 zeolite with a SAR $=8.2$ (ZSM-5-b).

Table 1 shows that the three high Al-containing ZSM-5 samples exhibit significant mesoporosity (between 21 and $26 \%$ of total porosity), being further confirmed by TEM image (ZSM-5-b sample, Fig. S20†). Finally, it is important to highlight that the quantity of Brønsted acid sites measured by $H / D$ isotope exchange technique ${ }^{19}$ confirms the unexpectedly low $\mathrm{Si} / \mathrm{Al}$ ratios suggested by elemental analyses. The yields of the different syntheses (based on $\mathrm{Si}$ ) were in the same range, i.e.; $52-64 \%$. By assuming an insertion of all $\mathrm{Al}$ present in the gel, a SAR $=8$ is coherent. It is however important to mention that
SAR8 material could also be obtained while using only half of the Al quantity in the gel $(0.08 \mathrm{~g}$ instead of $0.15 \mathrm{~g})$. Unfortunately, in the latter case, the synthesis yield based on Si was only $14 \% \pm 3$.

DFT calculations were performed to access the thermodynamic stability of ZSM-5 structure as a function of the SAR, to check if any thermodynamic limitation takes place preventing the formation of solids with low SAR. Purely siliceous zeolite was chosen as the reference energy for $\mathrm{SiO}_{2}$ units. Considering the system with the lowest SAR modeled $(=2,32$ aluminium and $\mathrm{Na}$ cations per unit cell) as a possible source for aluminium and sodium, the formation energy of each system of intermediate SAR considered (31, 15, 11, 8.6, 7, 5 and 3) was quantified (Fig. S22 $\dagger$ ). Positive values of the formation energy were obtained, showing the relatively high stability of purely siliceous system (SAR close to infinity) and SAR $=2$. The latter structure may thus be obtained without thermodynamic limitation as compared to intermediate SAR. The system exhibiting $n_{\mathrm{Al}}=12$, corresponding to SAR $=7$, is almost as stable as the two reference systems, substantiating the possible formation of ZSM-5 zeolite with SAR close to 8 as disclosed herein. Similar findings using force field were recently reported by Okubo et al. ${ }^{44}$ showing a sharp increase in the formation energy for $5<\mathrm{Si} / \mathrm{Al}<7$, which nicely match with our $a b$ initio calculations and the $\mathrm{Si} / \mathrm{Al}$ experimentally found. Fig. 2C depicts the three most stable cells found by the calculations.

\section{Acid catalysis}

To summarize the former section, the formation of a ZSM-5 zeolite with unprecedentedly low $\mathrm{SAR}=8$ value is now doubtless. The catalytic activity has been evaluated in two model acidcatalysed reactions: $n$-hexane cracking and the conversion of methanol into hydrocarbons. Though, a $1.64 \mathrm{mmol}$ of Brønsted acid sites per gram (Table 1) could be assessed by H/D exchange technique $^{19}$ (confirmed by elemental analyses), it is important to verify if all hydrons can be involved, or in other words if these acid sites are accessible in a catalytic reaction.

At the same degree of conversion $(X=7 \%)$, initial rates of $n$ hexane cracking of 3750 and $940 \mu \mathrm{mol}$ per $\mathrm{g}$ cat. per min were achieved for ZSM-5 SAR8 and SAR27 (reference) zeolites, respectively (Fig. 3).

As a priori expected based on Haag's observations, ${ }^{9 c}$ ZSM-5 SAR8 zeolite led to achieve a three times higher cracking rate 


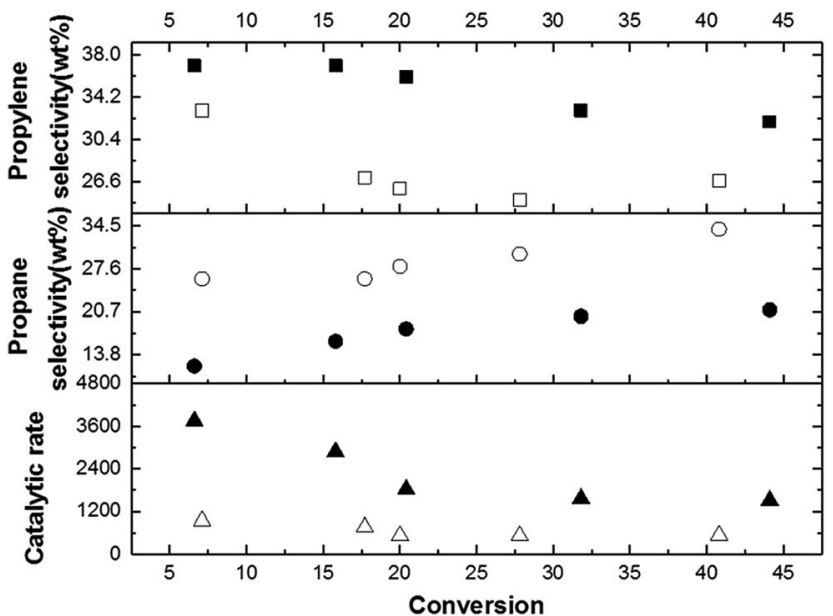

Fig. 3 Rate of $n$-hexane cracking (given in $\mu \mathrm{mol} \mathrm{g}{ }^{-1} \mathrm{~min}^{-1}$ ) and selectivities towards propylene and propane (\%) as a function of the alkane conversion for ZSM-5 SAR8 and ZSM-5 SAR27. Black and open signs correspond to ZSM-5 SAR8 and SAR27, respectively.

up to $40 \% n$-hexane conversion with respect to ZSM-5 SAR27 zeolite. This indicates that all hydrons present in the zeolite exhibit the required strong Brønsted acidity to perform alkane cracking chemistry, while at the same time guaranteeing the MFI-typical shape selectivity, demonstrated by the high share of propylene in the product distribution. ${ }^{31,32}$

Hence, such catalytic behaviour in alkane cracking further supports the absence (as shown by pyridine FT-IR) of nonvisible EFAl (neither oxides nor oligomeric species) which would significantly diminish the catalytic activity. ${ }^{42,43}$ The selectivity towards valuable propylene was found higher over ZSM-5 SAR 8 by $10 \%$ and $30 \%$ (in relative) than ZSM-5 SAR27 zeolite at conversions below $10 \%$ and superior to $20 \%$, respectively (Fig. 3). Likewise, ZSM-5 SAR8 led to lower propane selectivity, suggesting a decrease in hydride transfer secondary reactions. ${ }^{32}$ The high selectivity toward propylene (low in propane) is rather unexpected since the presence of numerous Brønsted acid sites may favour consecutive reactions, which seems not to be the case over ZSM-5 SAR8. However, based on aforementioned textural and structural properties, it is possible that an improved mass transport occurred in the double unit-cell system, as well as in the intercrystalline mesoporosity for propylene (Fig. S19 and S20†).

The catalytic activity of ZSM-5 SAR8 was further investigated in the conversion of methanol to hydrocarbons (Fig. 4). A classical methanol-to-gasoline behaviour with fast deactivation by coking could be observed, suggesting the presence of numerous Brønsted acid sites. Likewise the high selectivity towards hydrocarbons for ZSM-5 SAR8 (Fig. 4, inset), superior to $60 \%$ in the $\mathrm{C}_{5+}$ gasoline fraction, also supports the occurrence of several consecutive acid-catalysed steps within the zeolite pores. Considering the bicyclic nature of the autocatalytic methanol to hydrocarbons mechanism, it is reasonable to deduce a main occurrence, as a priori expected, of an aromatic-based autocatalytic cycle over ZSM-5 SAR8.

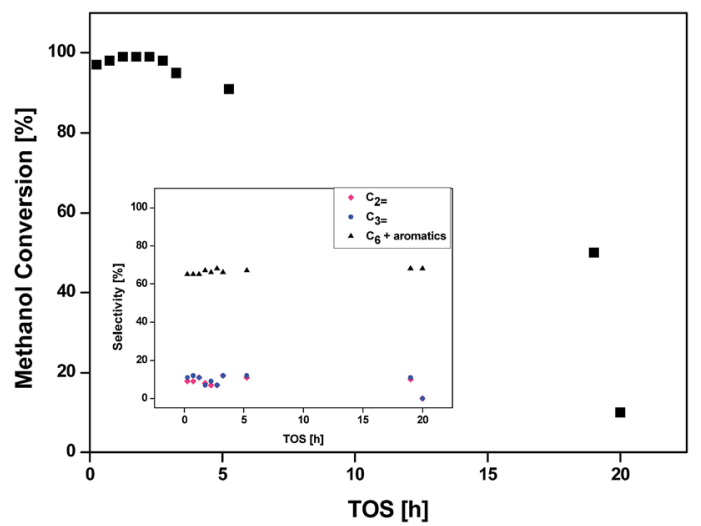

Fig. 4 Methanol conversion and selectivity towards hydrocarbons for ZSM-5 SAR8. Conditions: temperature $400{ }^{\circ} \mathrm{C} ;$ WHSV $=1.1 \mathrm{~h}^{-1}$ (experimental details are given in $\mathrm{ESI} \uparrow$ ).

\section{Discussion}

The use of biomass residues in the preparation of ZSM-5 was already reported and led to morphological and textural property changes, resulting in crystallite size around $50 \mathrm{~nm}$ without alterations in SAR values. ${ }^{29,30,33}$ In the present contribution, we have achieved an unprecedentedly Al-rich ZSM-5 while using an alkaline hydrolysate from sugar cane bagasse residues as an additive to classical hydrothermal syntheses.

Our strategy relied on modifying supramolecular interactions between silicates/aluminates and structure directing agent while adding a (bio-sourced) secondary template (BSST). This BSST may stabilise high Al-content MFI precursor as already observed in nature. ${ }^{34}$ Indeed, the natural counterpart of ZSM-5 zeolite, mutinaite mineral could be found with $\mathrm{Si} / \mathrm{Al}=$ 7.6. Likewise, ZSM-5 SAR8 sample belongs to the same space group (Pnma) but is built by two phases with slightly different unit cell parameters (Table $\mathrm{S} 2 \dagger$ ). Based on LC-MS analysis of biomass basic hydrolysate solution, it appears that organic species released in the solution are fragments originated from lignin, mainly $p$-coumaric acid, sinapyl and coniferyl alcohols. Besides, xylose and saccharose were also detected in the solution. However, the exact nature of those fragments remains unknown.

The occupancy of template cation has been refined to $4 \mathrm{TPA}^{+}$ per unit cell, being the maximum amount that can be accommodated per unit cell. This is not enough to balance the negative charge generated by the partial replacement of $10.7 \mathrm{Si}$ by $\mathrm{Al}$. Fortunately, the $\mathrm{Na}^{+}$content found by elemental analyses (6 $\mathrm{Na}^{+} /$u.c.) is almost enough to compensate the framework negative charge. Nonetheless, a homogeneous distribution of $\mathrm{Al}$ in the framework was assessed by ${ }^{27} \mathrm{Al}$ MAS NMR and TEM-EDX mapping (Fig. 2), thus zoning could be discarded.

BSST are involved in self-assembly mechanisms acting as structure directing agents, as well as metal-incorporation governing species, being of crucial importance in biology and potentially at the origin of life. ${ }^{35}$ Silicates ${ }^{36}$ and aluminates ${ }^{37}$ are known to bind to carbohydrates in a way that diminishes their reactivity. A parallel can be drawn with anti-freeze proteins 
(AFP), known to inhibit the crystalline growth of ice, ${ }^{38}$ thus rendering easier the understanding of complex phenomena occurring during BSST-mediated crystallisation. Similar experiments were conducted with alkaline hydrolysate aqueous solutions. In analogy to AFP's effect, freezing times were significantly increased (approx. 30\%) with respect to the synthesis in the absence of BSST at pH 11 (Fig. S22†). One can seek a parallel between AFP crystal growth mechanism and BSST role in crystallisation inhibition or structuration. Fig. 5 aims in tentatively describing the different steps involved in the BSST-mediated mechanism. As shown by LC-MS and GPC, an alkaline hydrolysis led to the release of monosaccharides as xylose or saccharose, evolving to partially oxidised, or aromatised carbohydrates to form negatively charged BSST species (steps 1 and 2, Fig. 5). Likewise, the three prominent alcohols of the lignin fraction are present as phenolate or alcoholate compounds. The presence of $0.16 \mathrm{mmol}$ of hydrolysed organic molecules in the gel prior to the synthesis was confirmed. It is reasonable to assume that during ageing, those molecules are changing in nature, interacting through non covalent forces and their chelating potential with aluminates and silicates (Fig. 5, steps 2 and 3), whereby large micellar structures may form. ${ }^{39}$

Kästele et al. evidenced that saccharides are able to expand the silicate tetra-coordination sphere to penta-coordinated trigonal bipyramids, even up to hexa-coordinated octahedra. ${ }^{39}$ To gain some insight into the supramolecular interactions, liquid phase NMR for the relevant $\mathrm{Al}$ and Si-nuclei was performed and model chelating molecules xylose and glucose have been chosen. Fig. S23† confirms the presence of pentacoordinated Si-atom after its interaction with xylose while an interaction with glucose could be discarded by ${ }^{29} \mathrm{Si} \mathrm{NMR}$ of the synthesis solution.

Besides, ${ }^{27} \mathrm{Al}$ NMR analysis of the solution showed a modification around $\mathrm{Al}$ nucleus, suggesting that at least one sugar

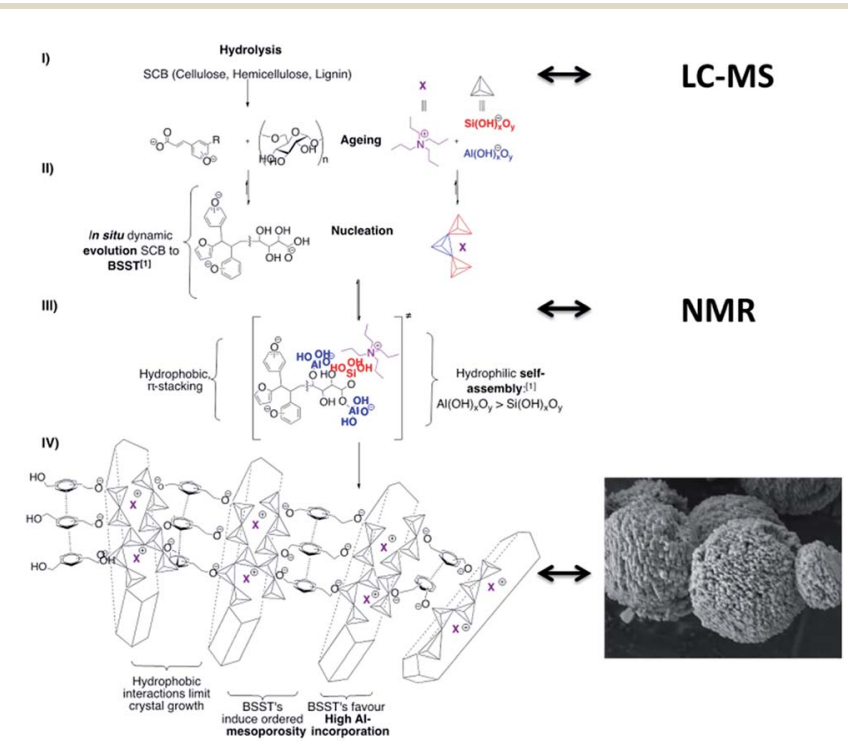

Fig. 5 Proposed self-assembly mechanism of aluminate, silicate species and BSST in solution, leading to elongated Al-rich MFI crystals formation. molecule is coordinated (Fig. S24 $\dagger$ ) whatever $\mathrm{C}_{5}$ or $\mathrm{C}_{6}$ sugar nature. ${ }^{45}$ One may therefore deduce, from those NMR data, that stronger interactions occur between organic molecules (BSST) and aluminates rather than silicates (step 3). Those evolving surfactant-like BSST molecules may interfere in the zeolite crystallisation process. Indeed, the preferred chelation to aluminates eventually could favour a higher Al-content in the final crystal. ${ }^{39,46}$ In addition, electrostatic forces maintain BSST species attached to the growing crystal, while aromatic species may stabilise, via $\pi$-stacking interactions, $a$ - and $b$-crystalline axes. Hence, Ostwald ripening might be prevented and the crystalline growth limited to the $c$-axis. Consequently, the high complexity of BSST species may also induce the formation of homogeneous mesopores (Fig. 5, step 4). It is worthy to mention that the addition of individual 'building blocks' (glucose, xylose, cellobiose, coumaric acid) to the zeolite synthesis mixture was attempted but did not lead to high Al-content MFI zeolite formation. Vilcocq et al. have recently demonstrated that the reactivity of hemi-cellulose under hydrothermal conditions $\left(140{ }^{\circ} \mathrm{C}, 24 \mathrm{~h}\right)$ differed from xylose or cellobiose. ${ }^{47}$ Thus, herein at least some intact polymeric lignocellulosic structure seems to be warranted to allow this complex mechanism to occur.

An analogy can be drawn to cryptates when alkylammonium and alkali cations cooperate to bind to sugars and silicates (aluminates), where numerous variations in the nature of the sub-units or of the bridges linking them are conceivable. ${ }^{\mathbf{4 0}}$ Zeolites are metastable phases, from which it is easy to shift from one structure to another. Rimer et al. addressed the complexity for understanding the zeolite phase(s) formation given the numerous parameters and their combinations involved in the zeolite synthesis. ${ }^{\mathbf{8 a , 1 1 , 1 3 , 4 1}}$

The strategy involving cheap BSST in the zeolite synthesis should allow bridging such metastability gap, overcoming $\mathrm{Si} / \mathrm{Al}$ limits and potentially designing new zeolite structures. Besides, other families of catalysts and materials may be rationally prepared with tailored properties for targeted applications in the future.

\section{Author contributions}

All authors contributed extensively to the work presented in this paper. P. L., E. S. G., A. V. and B. L. designed and performed the zeolite syntheses and catalytic experiments. S. S. and M. G. W. performed the high resolution electronic microscopy study. C. C. carried out the theoretical calculations. A. B. P. performed the XRD and Rietveld refinement. FT-IR interpretations were made by G. L., M. M. P and B. L. analysed output data, wrote the manuscript and financed the project.

\section{Conflicts of interest}

There are no conflicts to declare.

\section{Acknowledgements}

The technical assistance from Laetitia Valentin (Sorbonne Université), K. Soukup (ICPF) and T. Romero (ICPEES) was 
highly appreciated. A. B. P. thanks the Energy System Integration (ESI) platform at Paul Scherrer Institut for funding. She is indebted to Lynne McCusker for teaching her, patiently and playfully, the secrets of Rietveld refinement. C. Baerlocher from the Laboratory of Crystallography (ETH Zurich) is gratefully acknowledged for helpful discussions and Stef Smeets for his help in using Topas. The authors thank Nicola Casati and Antonio Cervellino from the Material Science beamline at SLS in Villigen, Switzerland, for their assistance with the powder diffraction measurements. M. M. P. is grateful to Petrobras for financial support. B. L. thanks the Region Grand Est for financial support. P. L. would like to thank the National Research Fund Luxembourg for his PhD grant (5898454). CNPq is also gratefully acknowledged for the support of the Science without Borders project No. 400508/2013-3.

\section{References}

1 A. Stein, S. W. Keller and T. E. Mallouk, Science, 1993, 259, 1558.

2 J. M. Lehn, Science, 1985, 227, 849.

3 J. M. Lehn, Angew. Chem., Int. Ed., 1988, 27, 89.

4 T. J. Barton, L. M. Bull, W. G. Klemperer, D. A. Loy, B. McEnaney, M. Misono, P. A. Monson, G. Pez, G. W. Scherer, J. C. Vartuli and O. M. Yagui, Chem. Mater., 1999, 11, 2633.

5 G. M. Whitesides and B. Grzybowski, Science, 2002, 295, 2418.

6 S. Ivanova, B. Louis, M. J. Ledoux and C. Pham-Huu, J. Am. Chem. Soc., 2007, 129, 3383.

7 M. P. Pileni, Acc. Chem. Res., 2007, 40, 685.

8 (a) A. I. Lupulescu and J. D. Rimer, Angew. Chem., Int. Ed., 2012, 51, 3345; (b) K. N. Olafson, R. Li, B. G. Alamani and J. D. Rimer, Chem. Mater., 2016, 28, 8453; (c) E. M. Gallego, M. T. Portilla, C. Paris, A. León-Escamilla, M. Boronat, M. Moliner and A. Corma, Science, 2017, 355, 1051.

9 (a) A. Corma, Chem. Rev., 1997, 97, 2373; (b) A. Corma and S. Zones, Zeolites as catalysts for the synthesis of fine chemicals, in Zeolites and Catalysis, ed. J. Čejka, A. Corma and S. Zones, Wiley-VCH Verlag GmbH \& Co. KGaA, Weinheim, 2010; (c) W. O. Haag, R. M. Lago and P. B. Weisz, Nature, 1984, 309, 589.

10 (a) S. Mintova, M. Jaber and V. Valtchev, Chem. Soc. Rev., 2016, 44, 7207; (b) M. Dusselier, P. Van Wouwe, A. Dewaele, P. A. Jacobs and B. F. Sels, Science, 2015, 349, 78; (c) P. A. Jacobs, M. Dusselier and B. F. Sels, Angew. Chem., Int. Ed., 2014, 53, 8621.

11 (a) A. I. Lupulescu and J. D. Rimer, Science, 2014, 344, 729; (b) J. Grand, H. Awala and S. Mintova, CrystEngComm, 2016, 18, 650; (c) A. Aerts, L. Follens, M. Haouas, T. P. Caremans, M. A. Delsuc, B. Loppinet, J. Vermant, B. Goderis, F. Taulelle, J. A. Martens and C. E. A. Kirschhock, Chem. Mater., 2007, 19, 3448; (d) S. A. Pelster, W. Schrader and F. Schüth, J. Am. Chem. Soc., 2006, 128, 4310; (e) E. A. Eilertsen, M. Haouas, A. B. Pinar, N. D. Hould, R. F. Lobo, K. P. Lillerud and F. Taulelle, Chem. Mater, 2012, 24, 571; (f) S. Kumar, Z. Wang, R. L. Penn and
M. A. Tsapatsis, J. Am. Chem. Soc., 2008, 130, 17284; $(g)$ J. Fedeyko, J. D. Rimer, R. F. Lobo and D. G. Vlachos, J. Phys. Chem. B, 2004, 108, 12271; (h) M. Castro, M. Haouas, I. Lim, H. J. Bongard, F. Schüth, F. Taulelle, G. Karlsson, V. Alfredsson, E. Breyneart, C. E. A. Kirschhock and W. Schmidt, Chem.-Eur. J., 2016, 22, 15307; (i) M. Castro, P. Losch, M. Haouas, W. Park, F. Taulelle, C. Loerbroks, G. Brabants, E. Breynaert, C. E. A. Kirschhock, R. Ryoo and W. Schmidt, Chem. Mater., 2018, 30, 2676.

12 (a) Y. Kamimura, S. Tanahashi, K. Itabashi, A. Sugawara, T. Wakihara, A. Shimojima and T. Okubo, J. Phys. Chem. C, 2011, 115, 744; (b) G. Majano, L. Delmotte, V. Valtchev and S. Mintova, Chem. Mater., 2009, 21, 4184; (c) B. Yilmaz, U. Müller, M. Feyen, S. Maurer, H. Zhang, X. Meng, F.-S. Xiao, X. Bao, W. Zhang, H. Imai, T. Yokoi, T. Tatsumi, H. Gies, T. de Baerdemaeker and D. de Vos, Catal. Sci. Technol., 2013, 3, 2580; (d) T. de Baerdemaeker, B. Yilmaz, U. Müller, M. Feyen, F.-S. Xiao, W. Zhang, T. Tatsumi, H. Gies, X. Bao and D. de Vos, J. Catal., 2013, 308, 73.

13 J. D. Rimer, R. F. Lobo and D. G. Vlachos, Langmuir, 2005, 21, 8960.

14 P. R. Willmott, D. Meister, S. J. Leake, M. Lange, A. Bergamaschi, M. Böge, M. Calvi, C. Cancellieri, N. Casati, A. Cervellino, Q. Chen, C. David, U. Flechsig, F. Gozzo, B. Henrich, S. Jaeggi-Spielmann, B. Jakob, I. Kalichava, P. Karvinen, J. Krempasky, A. Luedeke, R. Luescher, S. Maag, C. Quitmann, M. L. Reinle-Schmitt, T. Schmidt, B. Schmitt, A. Streun, I. Vartiainen, M. Vitins, X. Wang and R. Wullschleger, Synchrotron Radiat., 2013, 20, 667.

15 A. A. Coelho, J. Appl. Crystallogr., 2003, 36, 86.

16 A. A. Coelho, TOPAS-ACADEMIC, http://www.topasacademic.net/, v5.0., 2012.

17 Crystal Maker Software Ltd., UK, http:// www.crystalmaker.com.

18 J. Graesslin, PhD thesis, ETH Zürich, 2013.

19 (a) B. Louis, S. Walspurger and J. Sommer, Catal. Lett., 2004, 93, 81; (b) B. Louis, A. Vicente, C. Fernandez and V. Valtchev, J. Phys. Chem. C, 2011, 115, 18603.

20 S. Brunauer, P. H. Emmett and E. Teller, J. Am. Chem. Soc., 1938, 60, 309.

21 A. J. Maia, B. Louis, Y. L. Lam and M. M. Pereira, J. Catal., 2010, 269, 103.

22 (a) G. Kresse and J. Hafner, Phys. Rev. B: Condens. Matter Mater. Phys., 1994, 49, 14251; (b) G. Kresse and J. Furthmüller, Comput. Mater. Sci., 1996, 6, 15.

23 J. P. Perdew, K. Burke and M. Ernzerhof, Phys. Rev. Lett., 1996, 77, 3865.

24 S. Grimme, J. Comput. Chem., 2006, 27, 1787.

25 G. Kresse and D. Joubert, Phys. Rev. B: Condens. Matter Mater. Phys., 1999, 59, 1758.

26 C. Baerlocher and L. B. McCusker, Database of Zeolite Structures, http://www.iza-structure.org/databases/.

27 (a) C. A. Fyfe, G. J. Kennedy, C. T. De Schutter and G. T. Kokotailo, J. Chem. Soc., Chem. Commun., 1984, 541; (b) H. van Koningsveld, J. C. Jansen and H. van Bekkum, 
Zeolites, 1990, 10, 235; (c) M. A. Camblor, S. B. Hong and M. E. Davis, Chem. Commun., 1996, 425.

28 G. Coudurier, C. Naccache and J. C. Vedrine, J. Chem. Soc., Chem. Commun., 1982, 1413.

29 F. Ocampo, J. A. Cunha, M. R. de Lima Santos, J. P. Tessonnier, M. M. Pereira and B. Louis, Appl. Catal. A, 2010, 390, 102.

30 A. V. Silva, L. S. Miranda, M. Nele, B. Louis and M. M. Pereira, Catalysts, 2016, 6, 30.

31 B. Louis, M. M. Pereira, F. M. Santos, P. M. Esteves and J. Sommer, Chem.-Eur. J., 2010, 16, 573.

32 G. A. Olah, A. Molnar, S. K. Prakash and J. Sommer, in Superacid Chemistry, Wiley Ed., Hoboken, N.J., 2nd edn, 2009.

33 B. Louis, E. S. Gomes, P. Losch, G. Lutzweiler, T. Coelho, A. Faro, J. F. Pinto, C. S. Cardoso, A. V. Silva and M. M. Pereira, ChemCatChem, 2017, 9, 2065.

34 G. Vezzalini, S. Quartieri, E. Galli, A. Alberti, G. Cruciani and A. Kvick, Zeolites, 1997, 19, 323.

35 E. Y. Kostetsky, J. Biol. Phys., 2005, 31, 607.

36 (a) J. B. Lambert, G. Lu, S. R. Singer and V. M. Kolb, J. Am. Chem. Soc., 2004, 126, 9611; (b) T. Georgelin, M. Jaber, F. Fournier, G. Laurent, F. Costa-Torro, M. C. Maurel and J. F. Lambert, Carbohydr. Res., 2015, 402, 241.

37 U. Schilde, H. Kraudelt and E. Uhlemann, React. Polym., 1994, 22, 101.
38 F. Sicheri and D. S. C. Yang, Nature, 1995, 375, 427.

39 X. Kästele, P. Klüfers, F. Kopp, J. Schuhmacher and M. Vogt, Chem.-Eur. J., 2005, 11, 6326.

$40 \mathrm{~J}$. M. Lehn, in Supramolecular Chemistry: concepts and perspectives, VCH, Weinheim, Germany, 1995.

41 M. D. Oleksiak, J. A. Soltis, M. T. Conato, R. L. Penn and J. D. Rimer, Chem. Mater., 2016, 28, 4906.

42 D. E. Perea, I. Arslan, J. Liu, Z. Ristanović, L. Kovarik, B. W. Arey, J. A. Lercher, S. R. Bare and B. M. Weckhuysen, Nat. Commun., 2015, 6, 7589.

43 S. Schallmoser, T. Ikuno, M. F. Wagenhofer, R. Kolvenbach, G. L. Haller, M. Sanchez-Sanchez and J. A. Lercher, J. Catal., 2014, 316, 93.

44 K. Muraoka, W. Chaikittisilp and T. Okubo, J. Am. Chem. Soc., 2016, 138, 6184.

45 (a) A. Pallagi, Dalton Trans., 2013, 42, 13470; (b) X. Wang, C. Wang and H. Zhao, Int. J. Mol. Sci., 2012, 13, 15420.

46 J. A. Rendleman and J. E. Hodge, Carbohydr. Res., 1975, 44, 155. Even though no in cipher value of a preferable aluminate coordination could be found, the chelation preference by saccharides for aluminate species is striking since alumina columns, not silica are used for column chromatographies.

47 L. Vilcocq, E. Rebmann, Y. W. Cheah and P. Fongarland, ACS Sustainable Chem. Eng., 2018, 6(4), 5555.

48 C. A. Emeis, J. Catal., 1993, 141, 347. 